\title{
Navigating the Academic Job Market in Treacherous Times
}

William J. Miller, Southeast Missouri State University

Bobbi Gentry, Millikin University

ABSTRACT Doctoral programs take great care in assuring that students are prepared to enter the job market and become effective teachers and researchers. However, once faced with the daunting task of landing their first position, students are oftentimes left on their own. Given the current state of the job market-more applicants for fewer jobs-it is essential that students understand the process and what they should expect as they work to receive their first academic position. In this article, we walk students through the hiring process from deciding which jobs to apply for to handling contract negotiations.

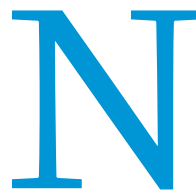

avigating the academic marketplace in hard economic times can be difficult, but does not have to be overwhelming. In an era of fewer jobs and more applicants, it is imperative that applicants understand the process of getting hired into an academic position. Possibly the most important part of the job search is to simply know who you are and where you want to go, which will help steer you toward the end of your graduate student career and the beginning of a sea of adventures.

\section{PRE-STEPS: PLANNING}

As a student, you should take advantage of as many professional development opportunities as possible. As soon as you begin graduate studies, join the American Political Science Association (APSA) and begin engaging with the wider profession. Starting to network and familiarize yourself with the discipline as early as possible will help you prepare for seeking your first academic appointment. Likewise, start attending conferences at the national or regional levels, even if you do not believe you are prepared to present immediately. By doing so, you can begin to understand what a good (and, maybe even more importantly, not so good) presentation looks like, as well as identifying some of the cuttingedge issues in the field. Membership rates for these organizations are discounted for graduate students, and some graduate programs are willing to pay a portion of their students' fees. Other opportunities available to graduate students include attending job talks given by Ph.D. candidates in your department, taking noncredit courses in teaching, writing book reviews and possibly articles for academic journals, presenting at regional conferences, and pursuing internal and external grant opportunities. If your academic department does not currently offer at least monthly

William J. Miller is an assistant professor of political science at Southeast Missouri State University. His research focuses on public opinion, campaigns and elections, and the scholarship of teaching and learning. He can be reached at wmiller@semo.edu. Bobbi Gentry is an assistant professor of political science at Millikin University. Her research focuses on youth voting, politics and the media, and campaigns and elections. She can be reached at bgentry@millikin.edu. professional development opportunities, try to create them as a student group or discuss the possibility of beginning such work with faculty members in the department.

Once you feel prepared and certain that you have good research to share, begin presenting at conferences. Conference presentations are largely the first attempt that graduate students make outside of the classroom to submit their work for peer review from others in the field. Given political science's reliance on peer review for everything from journal articles to book proposals, the earlier that students can get used to having their work critiqued by others, the better. Likewise, conference presentations can be invaluable at helping you begin to establish some name recognition within the discipline and your specialization. Good presentations can lead to offers of publication in edited books or journals, and can even help out with possible job prospects.

Know your own schedule to graduation and be sure that you are in conversation with your dissertation committee about your timeline. The committee will often respond to future employers' questions around the same time that you finish your dissertation. Given the need for departments to battle for tenure-track lines at many institutions today, it is unlikely that a department will risk hiring you if you have not finished your degree requirements in time to take the position. If you are hired as an ABD, you will usually have a lower salary and an instructor title rather than the title of assistant professor. Make sure your committee knows who you are and send them an updated CV and a general letter of application that highlights you. While you might generally expect future employers to only call your advisor, remember that in a tough market, employers will be looking for as many pieces of information that they can find about you as possible.

At least one year before you plan to begin the application process, look at the eJobs page on the APSA website. Observe how different institutions promote positions and how they talk about their institutions, and carefully review the timing of when positions are posted. Compared to other disciplines, political science has a very early timeline for hiring. Generally, tenure track positions are posted in the late summer and early in the fall semester. 
Some of the most competitive positions will be posted in August. This timeline is partly due to the early date of our national professional conference on Labor Day weekend, because employers want to be able to sift through their applicants before the conference to make a semi-short list. The hiring cycle generally runs through a variety of tenure track positions with deadlines of October through mid-December. After mid-December, the positions available will tend to be those in smaller liberal arts institutions and visiting professorships. Knowing that political science follows this very early application deadline cycle is extremely important for graduate students, because you need to begin planning which fall you would like to begin your career and pace your dissertation accordingly.

Know yourself when applying for positions. Where will you be happy? What research and teaching requirements can you handle? What type of institution best fits your interests and career plan? (see Gaff 2007) Where do you want to live? Are you willing to live in Alaska or outside of the United States? Knowing your needs and preferences will help you be genuine within the job competitive, you need to begin to think about these issues early in your graduate career. Knowing yourself also includes knowing the limits of your abilities. Are you able to teach a $4 \times 4$ teaching load? Can you teach lecture classes for over 100 students? Over 500? Under 20? You need to know the kind of atmosphere and institution for which you are best suited. Teaching experience can help you gain this knowledge. Talk with your advisor about your style regarding both teaching and research and reflect on where you think you fit. You have to know what you will want to do for the next few years, although not necessarily the rest of your life.

\section{STEP ONE: THE APPLICATION PROCESS}

Knowing where to find jobs is a valuable skill. At this point, we suggest becoming a member of the APSA, which also offers free access to eJobs. Cover all of your bases and also look into HigherEdJobs.com and postings listed by the Chronicle of Higher Education. While eJobs may cover more exclusively political science positions (including positions at research centers, think tanks, and policy centers), HigherEdJobs.com tends to list positions at

\section{While many do not believe there is any harm in taking the shotgun approach and sending}

applications to any job that is listed on eJobs, the first pile of rejections that a search committee creates is of the people who do not fit the position. Likewise, the individuals writing letters on your behalf end up recommending you for a position for which you are not well-qualified, which risks these individuals' reputation and influence and possibly decreases their enthusiasm for writing strong letters for you for those jobs for which you do qualify.

process and ensure that you end up in a position that you like, both professionally and personally. Fit really does matter when it comes to successfully getting a position and then being happy in that position. Candidates, especially those with thinner vitas, can often alter how they present themselves to appear to fit a position description. While this strategy may seem like a good idea, it can lead to a less-than-enjoyable first academic position. Colleagues will likely feel misled when they find out that your research agenda or actual expertise is not what they thought, and you will be expected to teach subjects for which you are not well-prepared and which do not connect to your research. In the end, both your research and teaching will suffer, and you will ultimately be less successful-and most likely less happy-than you could have been.

A difficult question to broach is where you might be competitive within the market. As academics, we live in a world of credentials. For a graduate student, your credentials include where you went to school, who your advisor was, what your dissertation is about, what you have published, whether you have received competitive grants or fellowships, and what the extent of your teaching experience is. Which credentials are the most important for you to attain varies depending on the institution, but these credentials generally stand across institutions. Even though you are only a graduate student, you are expected to have publications on your CV. During your graduate student career, ask to work with faculty members, and especially your advisor, on a coauthored work. Increasing expectations for graduate students to include presentations and publications on the $\mathrm{CV}$ is daunting, but to be smaller institutions and positions at community colleges. You do not necessarily need to limit yourself to particular schools or types of schools. While many do not believe there is any harm in taking the shotgun approach and sending applications to any job that is listed on eJobs, the first pile of rejections that a search committee creates is of the people who do not fit the position. Likewise, the individuals writing letters on your behalf end up recommending you for a position for which you are not well-qualified, which risks these individuals' reputation and influence and possibly decreases their enthusiasm for writing strong letters for you for those jobs for which you do qualify.

You must be realistic about your chances at many schools. Choosing specific institutions to which you send your materials could mean less time and heartache when you do not get a call back. Remember that each application packet takes hours to assemble, and rewriting parts of the packet to tailor it to each institution takes time and careful planning. If you are finishing your dissertation at a regional school, the tenure-track line at a top-ten program may not present you with the best job prospects. Also, remember that every application you submit will result in work for the individuals writing letters on your behalf. In some cases, you may be better off using a more targeted approach and applying only for those positions for which you believe you are realistically well qualified.

Make sure that you reread the advertisement before applying. How you craft your application packet depends on the position. Consider your application to be a narrative about the academic that you are. When you are narrating, consider your different 
audiences: R1 institutions want to see a coherent research agenda that has grant opportunities, whereas teaching institutions want to see teaching initiatives, innovations, and careful thought about teaching.

Your letter of interest is the first and possibly only element of your application that committee members may read, so make it count. In the style of any good narrative, you should open by connecting yourself to the position, outline your qualifications with either research or teaching, and conclude with how you are a good fit. We highly recommend that letters remain short-one to two pages, maximum. Most important, the letter should clearly be more than a form letter. Individualize this document for each job advertisement and position. Search committees can easily tell the individuals who put time and effort into the application package from those who are simply mailing the same materials to everyone. Be sure to send in your application materials as early as possible and call the departmental administrative assistant to make sure that they have a complete file. Often, schools will not inform applicants that their file has arrived incomplete, since they lack the staff capacity to contact these candidates in a timely fashion.

Your teaching philosophy should highlight your ability to connect with others and communicate information to students. Departments look for candidates who have some teaching experience so they do not have to worry about you making numerous rookie mistakes on their students. When necessary, use examples to illuminate your points. Be careful here not to contradict the points you have made in your statement of interest; the narrative should transition easily into the description of your teaching philosophy. Do not only tell the committee what you can teach, but also tell them how you will teach. Ask yourself what style you are: sage on the stage or guide on the side? How will you communicate difficult concepts? What professional development opportunities have you taken advantage of to prepare you for the classroom? For teaching institutions, the teaching philosophy portion of your letter of interest is where you can seal the deal and convince the committee that you are the ideal candidate. Do not be afraid to admit past failures in the classroom from which you have learned and ways in which you have changed. Committees look for a desire to teach and a willingness to try different things to create a positive and challenging learning environment for students.

For R1 schools, the emphasis is on a coherent research agenda. What has been your past success with receiving grants? In what direction is your research going? What skills or techniques gained throughout the research process do you plan to use at your new institution? What methods of research do you use? At R1s, your track of publishing and securing external funding are crucial indicators of future success. You also need to think about how your research can be collaborative with colleagues and possibly students.

\section{STEP TWO: PHONE INTERVIEWS}

Before the phone interview, do your own background research. Take the time to look at the institution, including the department web page, the college website, university information, and the department and/or university's mission statement. You may have general questions about the university and how you might see yourself there. Know who will be on your hiring committee and make a point of checking their profiles and recent work. Use the position description to determine what courses you may be asked to teach. Look over the department's learning goals, mission, and recent courses. Have an idea of what books you may consider using and how you might assess students in these courses. You will need to convince the committee that you are able to walk onto campus tomorrow and begin serving as an effective colleague.

Being nervous is expected, but you should be excited as well. At this point, the school has demonstrated interest in you. The first stage of the battle has been won. Be prepared for questions about why you want to be at that institution and why you are a good fit. What courses are you prepared to teach? How would you teach them? How will you engage in research? Have you applied for external grants for large projects? What will you bring to the department and the university as a whole? In addition to planning your responses, also prepare the length of your answers. Getting the right timing can be tricky, so remember this rule: take enough time to answer the question effectively, but do not ramble. Limiting how much you talk can be difficult, but for phone interviews, you must be considerate of the people on the other end of the line-who, in the end, will make the decision to hire you.

Be prepared with your own questions. If your interview is with a teaching institution, ask about its student body, faculty expectations, research and teaching balance, and departmental culture. If you are applying to a research institution, ask about institutional research support, matching funding with external grants, and opportunities that already exist within the department for continued research. The phone interview is not the place to ask about salary. The people with whom you speak on the call are most likely not the people who could offer much information about it, and the question raises red flags for the school regarding whether you would actually come if offered a position. Unless you think that the salary level might be unacceptable, it is best to save that discussion for negotiations following a formal offer. Likewise, do not ask any questions that you believe could even raise doubt regarding your interest in the position. There is no point in putting the cart before the horse.

\section{STEP THREE: ON-CAMPUS INTERVIEWS}

The on-campus interview is possibly the hardest part of the entire process, because it is a whirlwind adventure of meetings, first impressions, and traveling. Meetings will be booked pretty closely together, and after the first meeting, you will likely be running from one to the next for the rest of the day. Remember that two things are happening on this day: you are seeking to impress them, and they are seeking to impress you. If you have been invited to give a job talk, the school and department are trying to sell themselves to you as much as you are trying to sell yourself to them.

Do not be shy about asking to take a break during the long day. When you are being moved from office to office for one-onones, speak up and excuse yourself to the bathroom for a minute. No one is likely to tell you that it is time for a break, so make time yourself. Everyone with whom you visit has been in your position and consequently should understand. At meals, make sure you eat, but also leave room for discussion and be able to answer questions. One of the best ways to be able to eat at lunch is to ask questions. These informal sessions can sometimes be the most important opportunities for committees to determine how well you may mesh with the current faculty or students. Realize that with a tight schedule, unexpected things can happen. A colleague likes to tell a story about how his lunch host decided that he needed a special trip to a local cheesecake restaurant during his visit. While delicious, the host's trip led the candidate to miss a meeting with 
the provost. In situations like this, go with the flow. Mention the time and if ignored, make sure that the department is aware of why you were tardy.

For the on-campus interview, keep a few versions of your dissertation handy. Begin with the one-liner: my dissertation is about $x$-and keep the statement to only one line. If someone is interested, then he or she is likely to ask a follow-up question or say something like, "That is interesting," to which you can respond with a one-minute elaboration. In this iteration, hit the highlights but watch for hints to wrap it up (in most cases, these cues will be recognizable). For individuals within the discipline, prepare a five-minute-or-less conversation starter. In this version, make sure that your explanation summarizes the dissertation and research agenda. Talk about potential outlets and what you hope to do with the dissertation when completed. Nobody wants to hear a 30-minute monologue. Also, make sure you can describe your work in a way that faculty, undergraduates, and administrators alike can understand. Individuals with no knowledge of your topic (or even political science) may need to ask you about why your research matters, and you must be prepared to offer a persuasive explanation.

The job talk can be structured in two general formats. One format is the formal talk in which you present a chapter or a part of a chapter of your dissertation. If you have more recent work beyond the dissertation or are more than a year out from the dissertation, you may wish to choose a topic from your more recent research. The other format is a teaching demonstration, which can also be considered part of the job talk. Both of these talks demonstrate your ability to speak with others, how you communicate information, and, during the Q\&A, how collegial you are. Know the research background of the department. Do not go into detail on statistics if the department is majority qualitative. Be sure to ask for time (we suggest 20 minutes) to set up your presentation and practice on the spot. You may want to provide handouts if technology fails. Prepare for the formal job talk with a practice session in your graduate department and invite faculty outside of your dissertation committee and other students to give you feedback.

Prepare a teaching demonstration that fits your style, but be sure to leave room for questions. These demonstrations are meant to measure how a candidate engages students, how enthusiastic he or she is about the subject matter, and how well he or she communicates with an audience of students. Prior to arriving on campus, be sure to ask who the audience of your demonstration will be. Some departments will want to see how you interact with graduate students, and as a result, you will need to prepare differently. On campus, test any technology you may be using onsite before beginning the demonstration. If the technology fails, show that you are adaptable by continuing on without it. Faculty members know that these things happen and will be more concerned about how you handle the technological curveball than the fact that it happened. If you choose to use slides, be sure that they are well thought-out and beneficial to the class. Avoid slides that merely write out verbatim what you want to say. Consider the metaphor of giving your audience a kernel of information on the PowerPoint presentation: what you add to the kernel makes it pop, but you are the necessary ingredient. Consult with faculty members in your department before the demonstration and have them look over your planned presentation to make sure that you are not going to be presenting in a way that they believe could be viewed negatively.
You generally want to present course material that you have taught before and with which you have had success. In preparation for your teaching demonstration, ask your advisor if you might teach one of his or her courses for practice. In some cases, you might consider asking what the individual in whose class you will be teaching would normally cover in that class period. Speaking to the regularly scheduled class material can demonstrate adaptability and an ability to teach well on any subject matter. Most importantly, take this demonstration seriously. At teachingfocused schools, the opinions of undergraduate students can matter greatly. Likewise, at an R1, the department will rely on you to teach courses so that more senior faculty can devote time to research. In both circumstances, the teaching demonstration is more than simply showing that you can read off of a PowerPoint.

There are many things that you will want to highlight as part of an on-campus interview. If you have a regional tie to the area in which a school is located-particularly if the location is less than desirable on its face-emphasize this connection, especially during your meeting with the dean, provost, or president. Make sure you explain why you are interested in the school and the position. Know the faculty backgrounds well enough to be able to directly explain how you could see yourself fitting into the department. Ask questions about life in the area. If you have kids, ask about the school, parks, and libraries. Feel free to ask about community involvement and the relationship between the city or town and the university. On the same token, there are certain things that you should not do. Do not bad-mouth anyone in your graduate program, as this will make people feel like you would do the same regarding them. Likewise, do not mention negative opinions of scholars from other institutions beyond critical assessments of work or theories. A colleague once described how an applicant interviewing for a tenure-track position spent part of lunch speaking poorly about the personal attributes of a well-established scholar in the field, only to learn that this individual was the faculty member's dissertation chair. Most importantly, do not appear to feel negatively about any aspect of the school at which you are interviewing or members of the department. Word will get around.

First impressions matter, and you can never make a first impression twice. Consider how other people may perceive you. When you meet someone, never complain about anything. We have heard stories of colleagues not being hired because they complained that there was not a television in their hotel room. The assumption is that if you come in whining, you will continue to do so throughout your time at the institution. People shy away from negativity. At every meeting, make sure that you introduce yourself and greet the administrative assistant; these people have long memories, and the gesture also shows how you treat others, regardless of their status. Furthermore, once you are hired, you will quickly learn how invaluable these assistants truly are. Lunches with students matter. Meetings with deans matter. Meetings with provosts matter. Everything matters. We know of an individual who was not hired after a dean of general education declared her to be unacceptable as a result of statements she made regarding the general liberal arts education. From the second the plane lands until the time the wheels lift off, you are being interviewed.

\section{STEP FOUR: NEGOTIATION AND ACCEPTANCE}

If you arrive at this point, you have done many things right. The negotiation and acceptance stage can be the most stressful period of the entire application, because the process is now personal, and 
both sides have sunk costs into it. Almost everything can be negotiable, so always try to negotiate if you are unhappy with part of an offer. Salary is an obvious negotiation point; however, in hard economic times, salaries can move very little. You may ask, however, for other items that are less permanent to a university budget, such as a reduced course load, no committee service in your first year, a teaching assistant, a research stipend, or start-up technology funds. Some negotiating tools can concern nontraditional items such as department budget items, a speaker series for the institution, or specific research needs. Asking for benefits for others can do a lot to improve your standing in the department. It should be noted, however, that as budgets get tighter and tighter, there is considerably less room for new faculty to ask for benefits for either the department at large or other faculty members.

Negotiations in this particular market are particularly tricky. With schools receiving more applications than ever before, there is always someone else available. It is fair to be direct, but you must try to avoid appearing pushy or spoiled. If a school has offered you a position that you do not believe you are likely to accept regardless, it is safer to shoot for the moon in hopes of them coming back with an offer that changes your willingness to consider accepting. It is always best to ask for what you actually need, not what you want or, even worse, feel you deserve. Always try to justify the thing for which you are asking and frame the request in a way that shows the department and the institution how they will benefit from giving it to you. For example, frame a request for a reduced teaching load in terms of output. For example, if your workload is reduced by one extra course per semester, you will be able to work on this book and these two other projects. Do research on comparative salaries for the discipline as a whole (APSA is a useful tool in this endeavor) and for similarly situated universities (the Chronicle can be helpful) and use that information in the negotiation process. No matter what, always try to appear grateful for what you receive as a result of negotiations and accept that some things are nonnegotiable. In some states, for example, public employees cannot receive moving assistance. This is state law, not a frugal chair, dean, or provost.

If you are lucky enough to receive multiple offers, you have an even more difficult decision to make, but you also have more leverage. It is important to remember that you technically should have two weeks to decide on an offer. Some schools will attempt to tell you otherwise for a myriad of reasons. The process of accepting an offer can become particularly difficult if you receive an early offer while applications are still being processed at otherpotentially more attractive-institutions. Is one in the hand truly worth two in the bush? Turning down an offer in hopes of receiving a different offer later is a risky strategy, regardless of how qualified of a candidate you are. When deciding whether to accept an offer, you should feel free to communicate with members of the department to whom you feel you can relate. Ask them follow-up questions on the school and the community. At this point, feel free to pry a little more, as they have shown a vested interest in you. Faculty members will likely tell you if they are uncomfortable answering any questions you ask. Most importantly, make a decision that makes you happy. If you have not heard from other schools that you might prefer, call them, explain the situation, and ask for an update. Once you have another offer and a deadline, other schools may be more willing to disclose where they stand in their search. Talk with family and friends.
Run ideas past your advisors. Listen to what everyone offers and then ultimately do what is best for you.

An issue of special concern regarding negotiations is when a candidate has a trailing spouse whose placement is a critical variable in deciding whether to accept an offer or not. Given that many academics are married to academics, this issue continues to be important. Since potential employers are not permitted to ask about spousal issues and most candidates do not raise the concern early in the process, the question of spousal hires normally arises after an offer is made and a deadline is set. Candidates worry that transparently adding complications such as spousal hires to the equation can work against them in the hiring process, but deans and provosts need time to find placements for trailing spouses. Doing so in the two weeks after an offer is made and the trailing spouse is brought to light is often impossible. Candidates consequently always have a delicate trade-off to consider: mentioning the trailing spouse at an on-campus interview may reduce their prospects of an offer, but hiding the spouse until the offer is made significantly reduces the chances of a placement being found. However, you may ask the person who is making the offer, usually the dean, for ideas and suggestions on positions or institutions nearby, and they can help you make contact for potential positions.

\section{CONCLUSION}

We have witnessed the academic job market becoming more cutthroat as the economy tumbled and colleges and universities have become more selective in adding lines. As a result, it has become even more important for individuals to fully understand the daunting task of applying for political science faculty positions. While we hope the preceding discussion has clarified the general process, we wish to emphasize two key points in conclusion. First, every school is different in terms of both expectations and the hiring process. Creating standardized materials that can be easily modified to fit specific positions can help you quickly complete application materials. Second, it is important to not become overcritical of yourself as road bumps arise throughout the process. You will not get a call for every job for which you apply. Likewise, you will probably not be invited to campus after every phone interview or receive an offer to join every department you visit. During hard economic times, fellow graduate students from elite institutions are more likely to pursue positions that they would not normally take, which makes the stakes higher for all graduate students. These rejections are not likely a reflection on you. Regardless of what the position announcement states, most departments have an idea of what they are looking for regarding personality and research in a new colleague. Not getting an offer to continue with the process is not a condemnation of your skills or potential. It is simply one of the hardest lessons we can learn in graduate school. -

\section{NOTE}

We would like to thank Jill Dawson Miller, Jeremy Walling, and two anonymous reviewers for their feedback on drafts of this article.

\section{REFERENCE}

Gaff, Jerry G. 2007. "Faculty in the Variety of American Colleges." In The Academic's Handbook, ed. A. Leigh DeNeef and Craufurd D. Goodwin, 11-21. Durham, NC: Duke University Press. 